\title{
O DESENVOLVIMENTO DA CRIATIVIDADE NO APRENDIZADO DA EXPRESSÃO GRÁFICA PARA ENGENHARIA CIVIL
}

\author{
Vitória Aparecida Barboza Figueredo - vicbarboza@curvelo.cefetmg.br \\ Centro Federal de Educação Tecnológica de Minas Gerais - Campus Curvelo, Departamento \\ de Engenharia Civil e Meio Ambiente \\ Rua Raymundo Mattoso, 900 - Bairro Santa Rita \\ 35790-000 - Curvelo - MG
}

\section{Larissa Teles Rodrigues - rlarissa877@gmail.com}

Centro Federal de Educação Tecnológica de Minas Gerais - Campus Curvelo, Departamento de Engenharia Civil e Meio Ambiente

Rua Raymundo Mattoso, 900 - Bairro Santa Rita

35790-000 - Curvelo - MG

\section{Luciana Patrícia Ferreira - lupiferreira@cefetmg.br}

Centro Federal de Educação Tecnológica de Minas Gerais - Campus Curvelo, Departamento de Engenharia Civil e Meio Ambiente

Rua Raymundo Mattoso, 900 - Bairro Santa Rita

35790-000 - Curvelo - MG

Resumo: Tratando criatividade como inerente ao humano e tendo em vista sua importância para profissionais e equipes, este trabalho busca mapear a manifestação da criatividade na trajetória de aquisição conceitual/instrumental de Expressão Gráfica para alunos de Engenharia Civil ao longo dos 3 primeiros semestres do curso. Á partir da análise das metodologias aplicadas e de documentos produzidos com o apoio de distintos suportes instrumentais, foi possível perceber momentos distintos da manifestação criativa. Este tipo de reflexão pode auxiliar no estabelecimento de espaços educacionais que a estimulam $e$ promovem, reforçando traços motivacionais e pessoais, permitindo que o discente transmita o conteúdo de acordo com sua necessidade, expressando de forma autônoma durante o processo formativo. Foram analisados os projetos criados por alunos das disciplinas de Desenho do eixo de Expressão Gráfica do curso de Engenharia Civil do CEFET-MG/ Campus Curvelo.

Palavras-chave: Criatividade. Expressão Gráfica. Engenharia Civil.

\section{INTRODUÇÃO}

A linguagem é complexa e difícil; o visual tem a velocidade da luz. (DONDIS, 1997)

Na Teoria da Comunicação desenvolvida por Claude Shannon (1949) o processo de comunicação é composto pelos componentes: emissor (codificador do sinal); mensagem (instrumento ou veículo dos conteúdos); código (sistema de regras recíprocas que podem envolver sinais, formas escritas, gestos, sons); canal (meio de transportar a mensagem de forma manuseável, reprodutível, durável, conservável e resistente) e receptor (decodificador, 
destinatário, foco da comunicação). Código (regras) e canal (meio) devem ser de domínio dos usuários e compatível com o tipo de mensagem que se deseja transportar. Quando um dos elementos da comunicação se destaca, uma função da linguagem predomina.

Figura 1: Elementos da comunicação e (funções da linguagem).

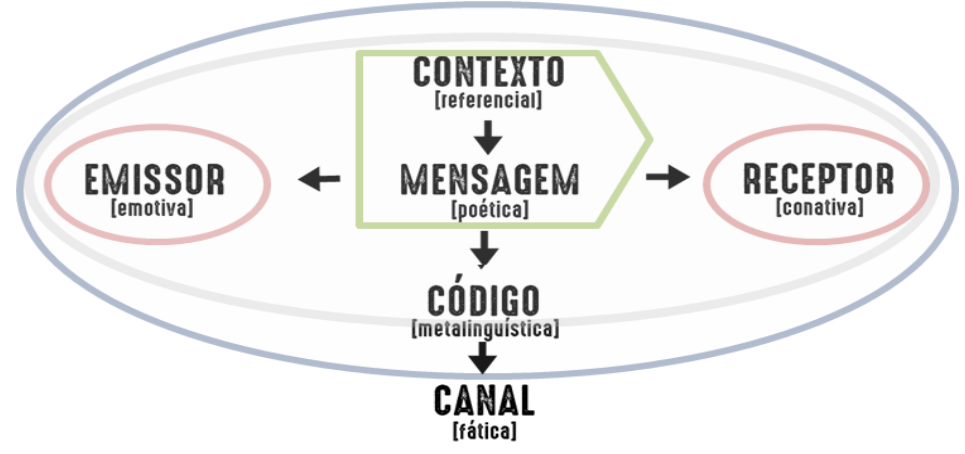

Fonte: Adaptado de www.acrobatadasletras.com.br

A partir da comunicação se sustenta uma comunidade. Mas para isso é necessário que emissor e receptor compartilhem uma linguagem, e consequentemente seus significados. Outro empecilho para a comunicação é o ruído que promove a interrupção.

Assim, a linguagem seria a ferramenta utilizada pela comunicação para transmitir os significados. Quando o receptor decodifica o sinal e obtém exatamente a mensagem que o emissor desejou transmitir, a comunicação se realiza. A linguagem, como a comunicação, pode ser verbal (oral/escrita) ou não verbal (gestos, desenhos, fotografias, imagens etc.). A escolha de elementos gráficos específicos e sua disposição no "discurso" visual, ou sintaxe visual, depende da aquisição de um vocabulário próprio, analogamente ao processo de aprendizagem da linguagem falada. A linguagem escrita pode ser considerada parte da comunicação visual. (PANIZZA, 2004).

Dentre todos os meios de comunicação humana, o visual é o único que não dispõe de um conjunto de normas e preceitos, de metodologia e preceitos definidos, tanto para a expressão quando para o entendimento dos métodos visuais... mas ... a sintaxe visual existe.(DONDIS, 1997,p.18).

$\mathrm{Na}$ comunicação visual artística, o desejo é que a mensagem emitida possa ser personalizada pelo receptor de acordo com sua interpretação por livre associação de seus elementos e espera uma resposta emocional ou instintiva. $\mathrm{Na}$ arte, a mensagem nos significados são ampliados e este é considerado um processo criativo.

No processo de comunicação visual técnica, se busca um resultado único, inequívoco e bem definido, aos quais são atribuídas características operativas cerceadas pela racionalidade técnica, e em geral, menos criativas. A questão é que, em disciplinas técnicas, a tendência à múltiplas interpretações, inerente à linguagem é cuidadosamente estipulada.

O desenho técnico reitera o objeto, representando sucessivas representações que reiteram a realidade comunicada e delimitando, desejavelmente de forma inequivocamente, o objeto (mensagem). Este processo é cercado de cuidados instrumentais e cada vez mais tecnológicos. A representação do mundo tridimensional, complexo, detalhado já foi exclusividade dos protótipos, nem sempre viáveis na engenharia, e cada vez mais acessíveis, com o auxílio de 
ferramentas de realidade virtual e aumentada 3D+. De fato a inerente criatividade humana, mediada instrumentos, nos aproxima da singularidade e pode ser atribuída à própria natureza dos estágios evolucionários que levaram ao desenvolvimento do nosso córtex cerebral e seus processos cognitivos (KURZWEIL, 2005).

Dentro do contexto da aproximação do humano com suas ferramentas das linguagens que universalizam as comunicações humanas, como a visual, nos interessa averiguar a criatividade dos estudantes de engenharia a partir da análise de sua produção em linguagem visual técnica. Identificar manifestações criativas mesmo quando permeada por métodos e instrumentos. Identificar possibilidades de ampliar esta expressão.

\section{REFERENCIAL TEÓRICO}

A expressão gráfica tem um papel ativo e modificador, sendo um intermediador no processo projetivo. Embora cada ser humano tenha percepções visuais e espaciais diferentes, todos tendem a gerar desenhos que se aproximem do idealizado, assim, o desenvolvimento do projeto ocorre de maneira menos rígida, disposto sobre certa ambiguidade que é depositada nas suas ferramentas, além de permear um ambiente propício à criatividade (RIGUI; CELANI, 2008). A partir dessa compreensão, é possível gerar espaços acadêmicos em que a criatividade se expanda tanto na prática, quanto na aplicação de projetos da Engenharia Civil.

Muitos alunos de engenharia se assumem imediatamente como não criativos pelo fato de não produzir uma experiência artística. Mas isso não é necessariamente real haja vista que o trabalho desenvolvido por um profissional arquiteto tende a ser considerado um trabalho criativo, de invenção, delimitado e estimulado por um processo permanente de negociação a partir de todas as variáveis presentes no processo (CAMPOMORI, 2016).

Sob o olhar do trabalho de Dondis (1997), o homem, ao desenvolver as habilidades necessárias para o uso da linguagem visual, desenvolve também seu poder criativo, tornandose conhecedor desta forma de comunicação. Analisar e buscar compreender a manifestação da criatividade e independência no processo de aprendizagem do aluno pode auxiliar no estabelecimento de espaços educacionais que a estimulem e promovam, reforçando traços motivacionais, adaptação a personalidades e habilidades de se expor em diferentes visões. Apesar da experiência humana se estabelecer em um mundo dimensional, o ser humano tende a conceber a visualização em termos de uma criação de marca, ignorando os problemas especiais da questão visual que nos são colocados pela dimensão.

Essa aprendizagem conecta-se à processos neurais, de modo que, o cérebro reage aos estímulos do ambiente, tornando-os mais "intensos" e fortalecendo as redes neurais, que se estabelecem com mais facilidade através de atividades prazerosas e desafiadoras. A cada novo estímulo, bem como, a repetição de um comportamento que seja estabelecido, circuitos processam as informações, que posteriormente são consolidadas, compreendendo que o uso de estratégias adequadas em um processo de ensino dinâmico e prazeroso provocará consequentemente, alterações na quantidade e qualidade destas conexões, afetando assim o funcionamento cerebral, de forma positiva e permanente, com resultados extremamente satisfatórios (MIETTO, 2012). 
Figura 2 - Processo espiral de adensamento dos conceitos de Expressão Gráfica .

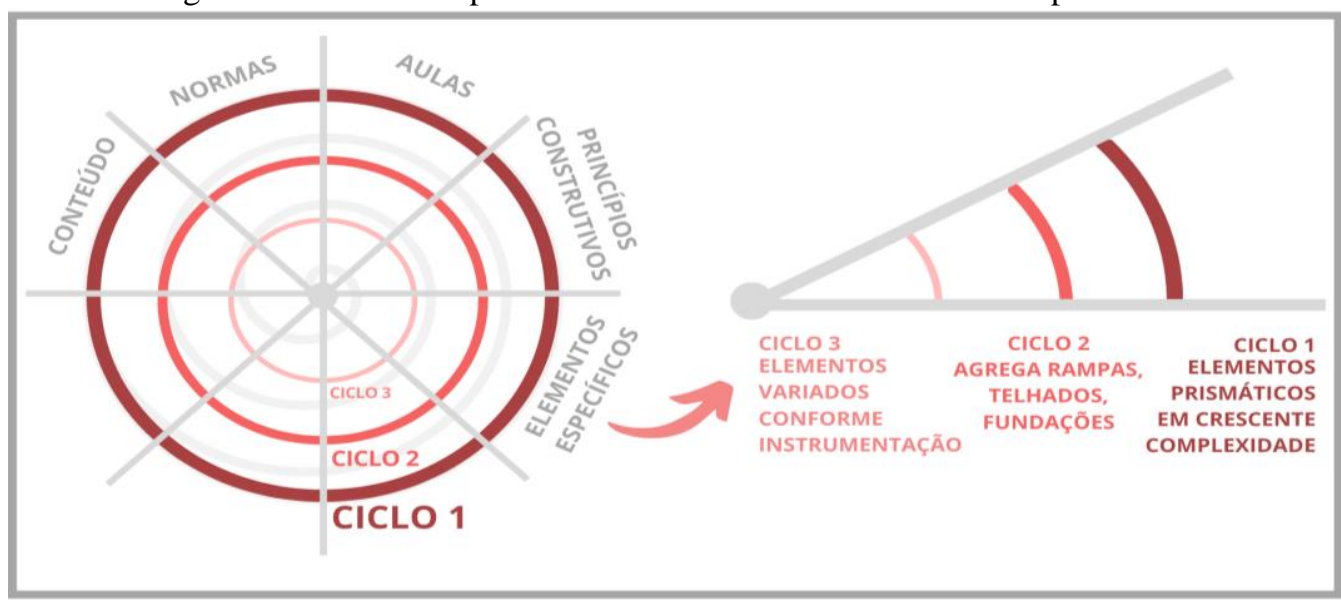

Fonte: Autoras.

Disciplinas sucessivas são tradicionalmente dispostas conforme a teoria da aprendizagem de Bruner (MARQUES, 2002) a partir dos conceitos de prontidão e de aprendizagem em espiral. Para ele a prontidão se justifica porque "as bases essenciais de qualquer disciplina científica podem ser ensinadas em qualquer idade de forma genuína" e a aprendizagem em espiral pelo fato que "qualquer ciência pode ser ensinada, pelo menos nas suas formas mais simples, a alunos de todas as idades, uma vez que os mesmos tópicos serão, posteriormente, retomados e aprofundados mais tarde". Atualmente o conceito de espiral do conhecimento foi retomado em conceitos de gestão focada no aprendizado dinâmico em grupos e instituições.

Uma ferramenta recorrente utilizada como base espiral é o uso da lógica booleana tridimensional (real/virtual). "A álgebra booleana recorre a operações intuitivas que equivalem ao trabalho real de juntar, recortar, perfurar ou serrar, mimetizando as operações possíveis com elementos materiais. Este formato de obter a representação gráfica, amplia sobremaneira o espectro de usuários imediatamente aptos ao seu uso e seu conceito pode ser utilizado independente do uso de ferramentas computacionais." (FIGUEREDO et al., 2019). A partir da aplicação dessa lógica o aluno recebe uma ferramenta que o acompanha durante os ciclos de composição do aprendizado e apela para o sentido de prontidão, mas também a processos lúdicos e de simulação da realidade.

Essa utilização se consolida quando associada aos processos da "cultura maker" com o aprendizado a partir da experimentação e prototipagem, como a impressora 3D. Dentro desse espaço "maker", o estudante assume o papel de protagonista e constrói o seu conhecimento a partir de experiências que envolvem erros e reparos constantes, criando conexões com o mundo real e estimulando a resolução de problemas com o apoio do professor como um facilitador e auxilia o aluno a se questionar sobre os próximos passos do projeto (SILVA; VILLAS-BÔAS, 2019).

Embora as ações descrição-execução-reflexão-depuração estejam sendo apresentadas de modo independente e sequencial, na prática elas podem ocorrer simultaneamente. Essa separação é feita para poder compreender o papel de cada uma no processo de construção de conhecimento. Por exemplo, durante a execução, à medida que o resultado vai sendo produzido, o aprendiz pode estar refletindo. Portanto, a melhor representação desta espiral poderia ser um redemoinho onde as ações estão ocorrendo simultaneamente (VALENTE, 2018). 
De acordo com o PPC, este curso, o primeiro processo é realizado no desenho técnico que apresenta métodos e ferramentas para visualização de vistas planas, cortes, formas e dimensões de acordo com cada necessidade de projeto. Em seguida, o desenho arquitetônico com forma de expressão, assim como a comunicação verbal ou escrita, que utiliza linhas, traçados, números, símbolos e indicações textuais, normalizadas internacionalmente, para representar de forma bidimensional a forma espacial de um projeto desenvolvido através de uma "prancheta eletrônica" realizando a transição do 2D para o 3D . (SARAPKA et at., 2009)

Por fim o Building Information Modelling (BIM), baseado na produção de modelos digitais 3D paramétricos de construção, alimentados por informações (custos, especificações e outros). É destacado como processo para produção de informação, atribuindo função e comportamento aos elementos de uma edificação, constituindo se uma base de dados comum e integrada, capaz de fornecer informações organizadas, envolvendo múltiplos stakeholders em diferentes fases do ciclo de vida de uma edificação. Este processo pressupõe interoperabilidade entre sistemas de diferentes fabricantes e capacidade de simulação (avaliação de impacto das decisões para todas as interfaces do edifício, seus custos e eficiência energética, incluindo pós-ocupação) (COMARELLA; FERREIRA; SILVA, 2016).

\section{OBJETIVO}

Analisar o surgimento de rompantes criativos, através dos processos de aquisição de conhecimentos e instrumentalização dentro da estrutura do curso de Expressão Gráfica para estudantes de Engenharia Civil. O procedimento se baseia na análise de sua produção em linguagem visual técnica, além de verificar manifestações criativas mesmo quando permeada por métodos, instrumentos e identificar possibilidades de expandir esta expressão. Permitir a expressão dessa criatividade a partir da exploração de aspectos da cultura maker a partir da prototipagem de suas criações.

\section{METODOLOGIA}

Para este trabalho utilizamos pesquisa de natureza qualitativa e documental, com método de análise de conteúdo. Foram analisados, ao longo de um semestre, os projetos criados por alunos das 3 disciplinas iniciais de desenho do Eixo de Expressão Gráfica do curso de Engenharia Civil do CEFET-MG/ Campus Curvelo. De acordo com o Projeto Pedagógico do Curso, essas disciplinas se adequam ao cumprimento de tarefas cíclicas progressivas de aprendizado. Elementos construtivos recorrentes são explorados em nível crescente de complexidade das habilidades: conceituais e instrumentais. Esta proposta reforça os níveis de instrumentação BIM (figura 3) nos quais os equipamentos se mostram cada vez mais associados ao uso de equipamentos computacionais. 
Figura 3 - Instrumentalização de Expressão Gráfica sobre Gráfico de Níveis de Maturidade BIM.

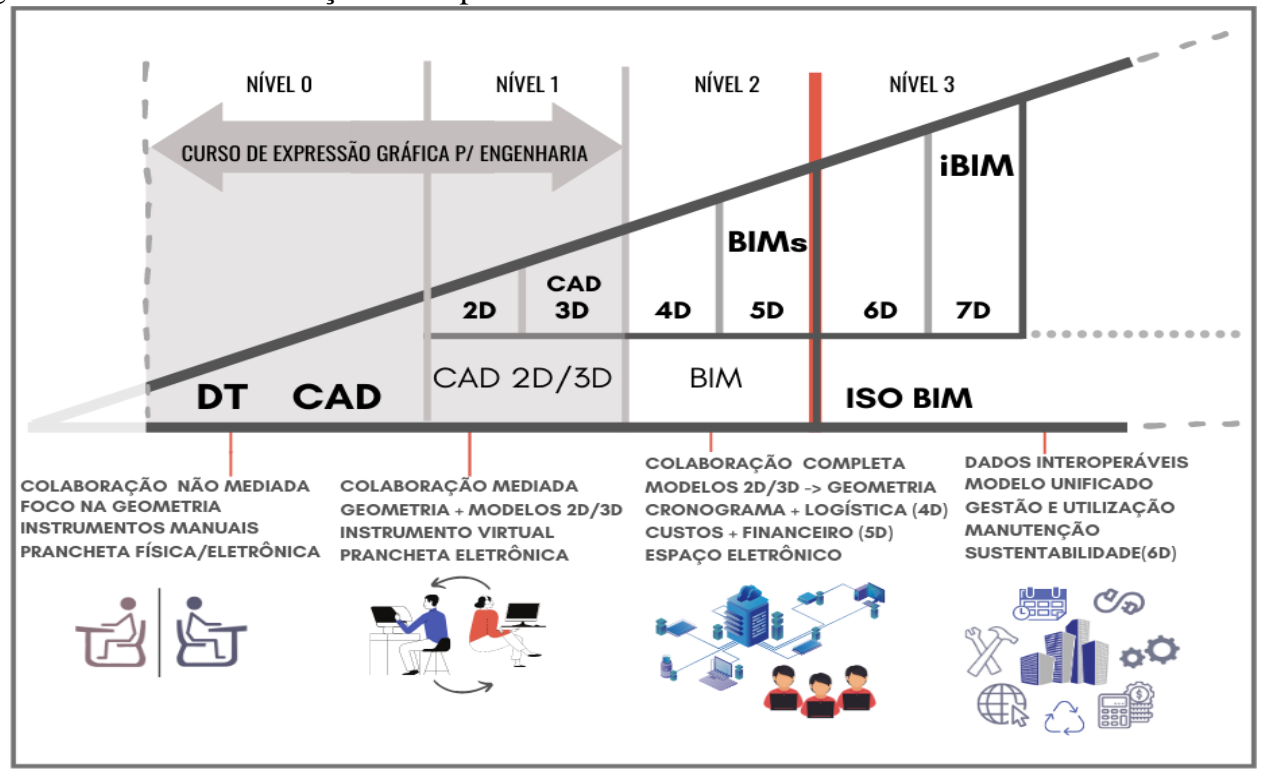

Adaptado de: Oliveira 2016 apud BIZ, 2011

Em cada etapa metodologias ativas, híbridas e simultâneas podem ser aplicadas de forma não excludente e combinada, de modo a fomentar espaços para a emergência criativa.

Percorremos os trabalhos desenvolvidos no período, fazendo levantamento das evidências de soluções de caráter extraordinário, ou seja, que não foram demandadas, emergindo espontaneamente durante o processo. Associamos a estes trabalhos caráter criativo oriundo da superação da etapa de aquisição da técnica / apropriação das ferramentas às quais o aluno foi exposto. Consideramos que a desenvoltura e segurança do aluno em seus desenhos e modelagens pode ocorrer sem não demonstrar criatividade inovadora, mas é um processo que desafia a engenhosidade para montagem das peças e destreza na expressão das soluções.

O levantamento procurou reconhecer, por outro lado, a busca da lógica associativa e da implementação das ferramentas disponíveis em cada etapa como é o exemplo do emprego de operadores Booleanos. Analisamos do emprego sucessivo das ferramentas e seus resultados no que tange à forma, complexidade, densidade e integração das peças e modelagens.

O diagnóstico do processo de aquisição da técnica ocorreu por ciclos e incluiu, desde a produção de perspectivas isométricas, até suas projeções planas instrumentalizadas em prancheta e croquis à mão, passando pela transição para prancheta eletrônica, e a representação de sistemas estruturais com uso de softwares BIM.

\section{RESULTADOS E DISCUSSÕES}

Analisamos que a experiência adquirida nestes trabalhos, ao longo de cada etapa, fixaram uma base conceitual sólida, além disso, observamos que o "protagonismo" do aluno, que foi incentivado em todo o processo, possibilitou mais liberdade e autonomia no uso das ferramentas e na expressão de seus rompantes criativos tornando-o apto a qualquer desafio.

$\mathrm{Na}$ figura 4, encontramos uma amostra da matriz diagnóstico de trabalhos finais apresentados pelos estudantes de expressão gráfica. Nas colunas, são representados os 3 ciclos de aprendizado com conteúdo espiral associadas a incremento tecnológico na instrumentação. Nas linhas é possível apreciar a complexidade crescente e soluções criativas resultantes de associação. Permeando o processo a adoção de metodologias híbridas, ferramentas conceituais 
e técnicas dinâmicas para o desenho. Em todas as etapas é exortada a criação das peças pelos próprios alunos que devem se basear em sua própria experiência para criar.

Figura 4 - Ciclo de aprendizado/informatização X complexidade/criatividade nos processos individuais.

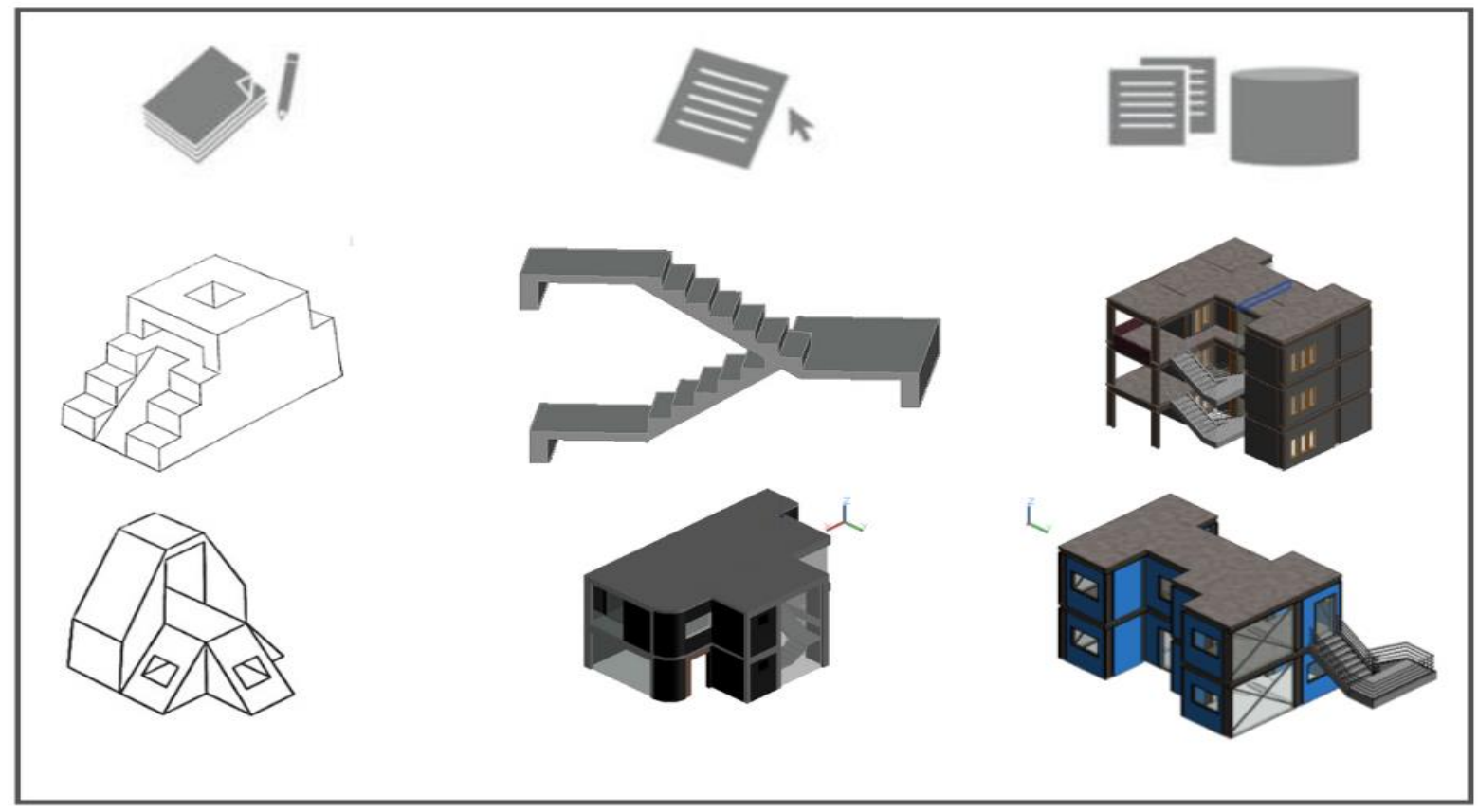

Fonte: Arquivo pessoal.

A primeira coluna apresenta exemplos de representações isométricas instrumentalizadas a mão com uso de prancheta. Esta é a etapa mais abstrata pois os alunos é o primeiro momento no desenvolvimento da capacidade de observação orientada do seu entorno. A orientação é que procurem desenhar formas com possibilidade de ser edificadas. Na segunda coluna observamos as produções em CAD com possibilidade de modelagem livre. Nessa etapa se estimula que os alunos simulem estruturas de concreto armado, mas o objeto é arquitetônico/estrutural. Na terceira e última etapa observamos as modelagens BIM com a utilização de famílias de estruturas metálicas. Observamos montagens mais rígidas, resultado das primeiras interações com um software de proposta mais estrita, porém ainda assim a busca por organicidade nas plantas e transparências ameniza a linguagem modular.

$\mathrm{O}$ uso multidimensional das capacidades associativas propulsionando pelo desenvolvimento do potencial de modelagem e compreensão formal, dá suporte ao processo de materialização e gestão dos objetos característicos da Engenharia Civil.

A figura 5 abaixo ilustra o processo de desenvolvimento espiral em sua crescente complexidade. Iniciando no primeiro ciclo com sua geometria elementar e evoluindo para o detalhamento arquitetônico seguido do refinamento da representação das estruturas construtivo específicos para as coberturas na Engenharia Civil. Simultaneamente observamos as etapas de transição BIM sendo aplicadas. Na primeira figura (BIM 0) com a instrumentação manual em croqui/prancheta física. Na sequência em prancheta eletrônica e apoio de software CAD 2D e 3D (BIM1). Na etapa final a estruturação a partir de famílias BIM que possibilitará futuros níveis integração (BIM2). 
Figura 5 -.Evolução da forma oblíqua a telhado/ evolução de booleana a escada
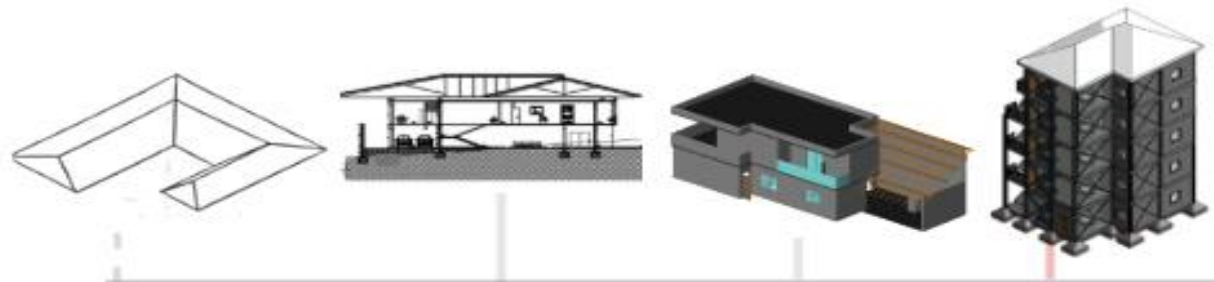

Fonte: Arquivo Pessoal.

A evolução do elemento cobertura, desde seus fundamentos geométricos até sua formalização como elemento construtivo passando pela adequada aplicação em situações não demandadas/inusitadas, sinaliza mais que inclusão desta representação no elenco da linguagem gráfica individual apontando para a emergência criativa.

$\mathrm{Na}$ etapa final de cada ciclo, a pesquisa em prototipagem é proposta tanto a partir do croqui a mão quanto a partir do modelo 3D CAD. A fusão das técnicas permite outros olhares e apropriação sobre a forma do objeto. Conforme sequências a seguir:

Figura 6 - Etapas de prototipagem a partir de Desenho Técnico e a partir de Desenho Arquitetônico..

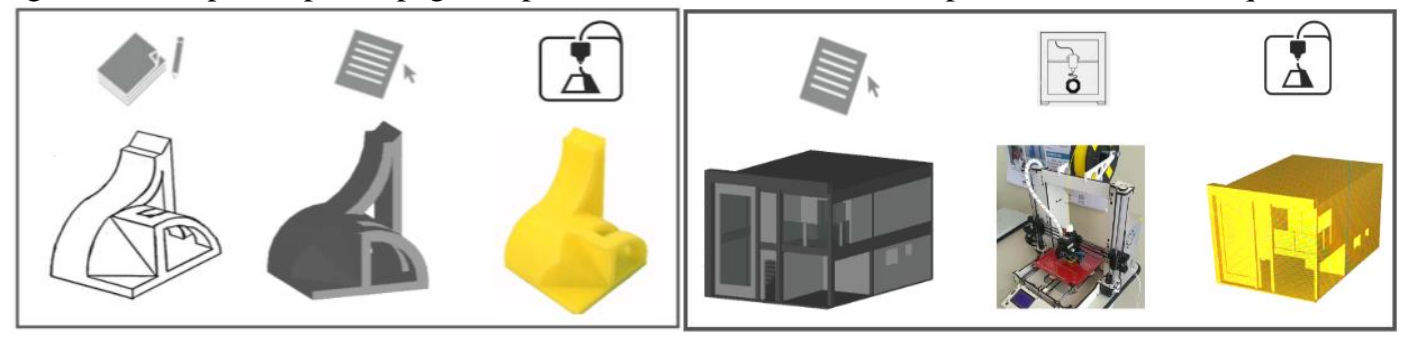

Fonte: Arquivo pessoal.

Nestas etapas observamos a aquisição de outras formas de instrumentação na técnica e desenvoltura no ajuste e configuração de equipamentos que vai demanda a compilação e combinação de soluções.

\section{CONSIDERAÇÕES FINAIS}

Neste trabalho, a emergência do processo criativo na produção dos alunos está ligada a apropriação tanto instrumental, quanto conceitual em cada etapa do processo espiral de adensamento dos conceitos de expressão gráfica, assim, foi possível observar todas as evoluções vão tornar o ambiente acadêmico propício à manifestação dos rompantes criativos.

Durante todo o curso o futuro engenheiro pode ser levado a exercitar sua criatividade associativa, ele começa a agregar suas experiências cognitivas de forma objetiva e conhecimentos oriundos de áreas diversas e aparentemente não relacionadas são a primeira matéria-prima. Suas ferramentas e técnicas passam a exercer influência ao longo do processo utilizado durante o projeto interferindo de forma relevante no desenho e consequentemente na obtenção de soluções.(RIGUI; CELANI, 2008).

Podemos observar que cada aluno tem uma maneira de se expressar e que fatores como o medo de errar e a insegurança podem inibir novas ideias e sua criatividade, por esse motivo iluminar a caixa-preta "flusseriana" dos instrumentos eletrônicos utilizados, ou seja, compreender as ferramentas e explorar todas as suas possibilidades além do superficial, é crucial para a evolução do aluno (FLUSSER, 2002).

Cada aluno aprende por métodos, estilos e ritmos diferentes de maneira que as tecnologias são instrumentos que complementam esse processo, além disso, a motivação é um fator chave 
para o processo de ensino e aprendizagem sendo uma experiência intrinsecamente motivadora (CHRISTENSEN, 2009). Para tanto, propiciar espaços acadêmicos que proponham e incentivem cada vez mais soluções apoiadas no desenvolvimento continuado da cultura maker e em desdobramentos críticos do futuro consumidor sobre a implementação de equipamentos/softwares gráficos é fundamental.

No que tange às vantagens do processo, além de fomentar e promover ao aluno ambientes que reforcem traços motivacionais, liberdade e seus rompantes criativos, estimulam à cultura maker e autonomia do indivíduo. Todavia, há o risco de desvanecer, em situações arbitrárias, nas caixas-pretas instrumentais/conceituais, já que, interferimos como usuários nas ferramentas em si.

\section{Agradecimentos}

Ao programa de monitoria Diretoria de Graduação (DIRGRAD/CEFET-MG) pela oferta das bolsas. Ao e DECMCV pela disponibilização dos espaços físicos e laboratórios. Ao DEE e Grupo NUTES (Núcleo de Tecnologia em Energia Solar) na figura do professor Allan Ferreira Pinto e seus alunos, pelo apoio na impressão 3D das peças. Ao CEFET-MG Unidade Curvelo e seus alunos Expressão Gráfica para Engenharia Civil.

\section{REFERÊNCIAS}

CAMPOMORI, Maurício José Laguardia. Racionalidade técnico-científica versus criatividade ou Algumas chaves para enfrentar o desconforto da arquitetura dentro da universidade contemporânea. In: Encontro da Associação Nacional de Pesquisa e PósGraduação em Arquitetura e Urbanismo, 2016, PortoAlegre. Anais Enanparq. PA, 2016.

CHRISTENSEN, C. M. Inovação na sala de aula: como a inovação de ruptura muda a forma de aprender. Porto Alegre: Bookman, 2009.

COMARELlA, Cristhian W., FERREIRA Éric V., SILVA Rafael K. P.; Níveis de Desenvolvimento BIM de Guias Nacionais e Internacionais - Estudo de caso Universidade Positivo- Curitiba, 2016.

DONDIS, Donis A. Sintaxe da Linguagem Visual. Tradução Jefferson Luiz Camargo. São Paulo: Martins Fontes, 1997.

FIGUEREDO, Vitória Aparecida Barboza, et al. Metodologias híbridas no ensino de desenho técnico para engenharia civil. In: XIII International Conference on Graphics Engineering for Arts and Design - GRAPHICA, 2019, RJ. Anais Graphica. RJ, 2019.

FLUSSER, Vilém. Filosofia da caixa preta: ensaios para uma futura filosofia da fotografia. Tradução do autor. Rio de Janeiro: Editora Relume Dumará, 2002.

KURZWEIL, Ray. The Singularity Is Near: When Humans Transcend Biology. Penguin Books, New York, 2005.

MARQUES, Ramiro. A pedagogia de Jerome Bruner. Consultado em http://www. eses. pt/usr/ramiro/docs/etica_pedagogia/A\% 20Pedagogia\% 20de\% 20Jero meBruner. pdf acedido em, v. 20, 2002. 
MIETTO, Vera L. A Importância da Neurociência na Educação. Novo Hamburgo- RS, 5 de abril de 2012.

RIGHI, Thales; CELANI, Gabriela, Esboço na era- Uma discussão sobre as mudanças na metodologia de projeto arquitetônico. In: Encontro de Convenção Científica de Engenharia e Arquitetura, 01 a 05 de Dezembro de 2008, La Habana-Cuba, XVI Congreso Sagradi. Cuba, 2008.

OLIVEIRA, João Pedro Diniz Flor de., Gestão do modelo BIM no âmbito do projeto de estruturas. Instituto Superior Técnico, Lisboa, Março de 2016. Disponível em: https://docplayer.com.br/72886433-Gestao-do-modelo-bim-no-ambito-do-projeto

-de-estruturas.html . Acesso em :23/09/2019

PANIZZA, Alexandre de Castro, Colaboração em CAD no Projeto de Arquitetura, Engenharia e Construção: Estudo de caso. Universidade Estadual de Campinas Faculdade de Engenharia Civil. Campinas SP, 2004.

SARAPKA, Elaine M., et at. Desenho Arquitetônico Básico. São Paulo : Pini, 2009.

SILVA, José Nilton da; VILLAS-BÔAS, Lucia. Aprender Engenharia: Contribuições da Cultura Maker. In: VIII Encontro de políticas públicas e formação de professores: diálogos e resistências no cenário educacional brasileiro, 03 e 04 de Setembro de 2019, Universidade Cidade de São Paulo. Anais Eletrônicos do VIII Encontro de políticas públicas e formação de professores. São Paulo, 2019.

SHANNON, Claude E. \& WEAVER, Warren. The mathematical theory of communication. Urbana, Illinois: University of Illinois Press, 1949.

VALENTE, José Armando. Aspectos críticos das tecnologias nos ambientes educacionais e nas escolas. Revista Educação e Cultura Contemporânea, v. 2, n. 3, p. 11-28, 2018.

\title{
THE DEVELOPMENT OF CREATIVITY IN LEARNING FROM GRAPHIC EXPRESSION FOR CIVIL ENGINEERING
}

\begin{abstract}
Treating creativity as inherent to the human and bearing in mind its importance for professionals and teams, this work seeks to map the manifestation of creativity in the trajectory of conceptual / instrumental acquisition of Graphic Expression for Civil Engineering students throughout the first 3 semesters of the course. From the analysis of the applied methodologies and documents produced with the support of different instrumental supports, we were able to perceive different moments of creative expression. This type of reflection can help in the establishment of educational spaces that stimulate and promote it, reinforcing motivational and personal traits, allowing the student to transmit the content according to their needs, expressing autonomously during the formative process. Projects created by students from the Drawing disciplines of the Graphic Expression axis of the Civil Engineering course at CEFET-MG / Campus Curvelo were analyzed.
\end{abstract}

Key-words: Creativity, Graphic Expression, Civil Engineering. 